\title{
Flight of Transcendence: \\ Exploring Flight as a Metaphor for Transcendent Teaching and Learning
}

\author{
Towani Duchscher \\ University of Calgary \\ trmduchs@ucalgary.ca
}

\begin{abstract}
This paper explores flight as a metaphor for transcendence in teaching and learning through an examination of Philip Phenix's (1975) work, “Transcendence and the Curriculum," combined with personal reflections, poetry, and an investigation of the scientific workings of flight. This journey of understanding begins with poetic reflections on the sensations of flight, including fear, boxed in limitations, and the motivation of our sense of wonder. The article then examines and interprets the four forces that act on an object in flight as metaphors for the elements of transcendent teaching and learning. The goal of this article is to understand the forces at work in our experiences of transcendence in the classroom and to remind us to run head first into the wind and soar.
\end{abstract}

Keywords: transcendence, teaching, learning, flight, metaphor

\section{Flight of Transcendence:}

Exploring Flight as a Metaphor for Transcendent Teaching and Learning

The moments in my life when I have experienced true learning and teaching have felt freeing and have been accompanied by the sensation of soaring. These moments were instances of transcendence, allowing me to rise above and go beyond what I thought I knew or was capable of, and what my students thought they knew or thought they were capable of doing and being. These encounters allowed me and my students to experience the scientific structure mixed with the poetic magic of flight, of transcendence.

tran'scend

verb (used with object)

1. to rise above or go beyond; overpass; exceed: to transcend the limits of thought; kindness transcends courtesy. 
transcend

mid-14c., from L. transcendere "climb over or beyond, surmount," from trans-

"beyond" + scandere "to climb" (see scan (v.)). ("Transcend," n.d.)

Philip Phenix (1975) notes that "spirit is the name given to the property of limitless going beyond" (p. 325). When we are filled with "spirit," we discover the infinitude of life and of learning and we are lifted and moved above and beyond our present place, our present expectations, and our present abilities; we begin to fly.

\section{Transcendence}

Flying takes us up, over, and beyond our present. When we land we are somewhere different, somewhere new. It is a journey. Flying fills us with excitement, exhilaration, and fear. We are excited about the prospect of new possibilities, new knowledge, and new places. Flying takes us into the unknown, leaving behind the comfort of the past, the comfort of our present ways of being and knowing, and it is frightening to venture out. Our desire for discovery pushes us past our fear into a full bodied experience of the exhilarating discovery of the magic of wonder and awe. Transcendent teaching and learning allows us to experience all of these sensations of flying, to soar through the classroom and curriculum as a murmuration of birds in flight.

\section{Flight Memory: March 19, 1998}

\section{Bloukrans Bridge (216 m. high Bunji Jump), South Africa}

I stand with my toes over the edge,

Terrified.

Legs shaking,

Heart beating wildly,

Wind whirling past my ears,

Blinking back tears,

I spread my arms... (and think about my technique?)

And all the possibilities.

I hear the count down 
And then...... jump!

I jump!

Flinging my body forward and out into the wide expanse of openness, Away from the concrete ground

Away from what is safe,

Into the unknown!

Screaming

Screaming

Screaming

With fear

With exhilaration

With joy!

\section{Flight Memory: September 5, 2000}

\section{High school classroom, Calgary, Alberta}

I stand at the front of the room, toes tipping over the edge of new experience. My arms hang stiffly at my sides, my hands shake. I have positioned myself slightly to the right side of the teacher's desk. It is my first day of teaching and I have conjured up every cliché moment from every new teacher movie I have seen. I am still shaking. I have to press harder on the chalk to keep my lines straight, fighting against the shaking. I have already written my name on the board and now I stand, in the new red suit that my mom helped me to buy, waiting at the front of the room for my class to enter, for my new life as a teacher to begin. $5,4,3,2,1 \ldots$ JUMP!

\section{Climb Over or Beyond, Surmount}

To experience transcendence in teaching and learning requires us to take risks, to push past the fear that wants us to stay where things are predictable and safe, and to venture out into the unknown. There are risks, but the experience of flight is so exhilarating and life changing that 
we must take the risk. We can take the risk if we realize and trust in the interconnectedness of our world. Knowing that we are all connected and trusting in our shared experiences can give us as teachers and learners a safety net, a tether to the bridge, the knowledge that we will be there for each other if we fall.

This flight will not be the same for each learner as we each will discover something different and chart our own, unique, path, together. Philip Phenix (1975) states that "freedom in the school of transcendence is based on openness to fresh possibilities of insight and invention and provision of ample cultural and interpersonal resources for the formation of unique structures of existence" (p. 333). This flight must start from being open to new ways of learning and teaching, and new ways of connecting with each other. We can't discover the magic of flight by doing the same worksheets year after year, or sticking to the same notes on each topic, year after year. The magic comes from wonder and awe, from unanswered questions and their exploration and discovery, from flying beyond the boxed walls of our past.

\section{Boxed in with Fear as My Companion}

The school world is filled and framed by boxes and boundaries. Our schooling space is a large box broken into smaller, inner, boxes. Within our own individual boxes, we store our books and supplies in one series of boxes and we store our students in another. Our calendars, which help us plan our year, our months, our days, are yet another series of boxes within boxes. Our subjects are isolated in boxes and our assessments box in our time to explore. We check off boxes of knowledge and skills acquired, curricular outcomes reached. Each of these boxes gives us a finite amount of set space, of resources, of time, in which to accomplish the openness of discovery and the beauty of flight. We could spread our wings to fly, but often we don't. We stay earthbound, within the confines of our boxes.

\section{Boxed In}

"We have a lot to cover before the test."

"Finish the worksheets."

"Sit down."

"Not enough time."

"I'd love to do more interesting teaching, but I have to prepare them for the achievement tests." "Sit down."

"You can't teach that, we have to teach step aerobics." 
"Sit down."

"You need to lower your expectations."

"Quiet."

"Your son wiggles too much. Sometimes he even stands up!"

"Sit down!"

\section{Box Memory: September, 2, 2004}

\section{English 10 classroom, Calgary, Alberta}

Teaching both English and Dance makes me a transient teacher. I am always sharing a classroom with at least one other teacher. This year I am sharing with a kind, experienced teacher in his last year of teaching. He gives me a tour of "his" classroom and then at the end he shows me the chart. The seating chart. The seating chart holds court from its own coveted spot on the podium at the front of the classroom. It seems to have a more valued place in this room than I do, as I stuff my books and pencils into my portable bag and shove it into an empty corner of the room.

My colleague gives me a tour of the chart as well, outlining its importance. He informs me that the desks must be kept in this exact order, that each row has a specific number of desks, all facing the front, and that it is imperative that this order be preserved and honored. I assure him that I understand. On the first day of school, I like to move the desks into a circle, so that my students and I can see each other and get to know each other. My colleague walks into the classroom to get something from "his" desk and stops dead in his tracks. He is visibly shaken by this desk movement. At the end of the class, the students and I move the desks back into the "correct" order, following the seating chart. But my colleague is clearly nervous. For the next two weeks, he lingers in the room as I begin to teach, uncomfortable about the possibility of disrupting "the seating plan".

Every day the students and I move the seats back into the correctly, ordered and numbered rows. My colleague stands and watches every lesson. He watches as we move the desks to the periphery of the classroom so that we can explore movement and physical ways of creating symbolism. He watches as we move the desks, so we can create movement tableaux performances of the plot of stories. He watches. After two weeks of watching and realizing that the desks always return, he stops watching. He trusts me to honour "the seating chart". 


\section{Run into the Wind}

We are encouraged to stay where it is safe and predictable and known. It is frightening to stand with our toes wriggling over the edge, looking out at the infinite possibilities and the chance of soaring but also the chance of falling. We are kept inside the box by our fear. However to be ruled by fear is painful. We know of the outside world, we know of the infinite possibilities. To deny our own transcendence, to deny ourselves the chance to fly beyond our limitations, our present, our known, is to deny ourselves the magic of learning and teaching. We are boxed in, but our wings are not clipped. We can choose to discover the magic of wonder, of awe, of learning. We can choose to spread our wings, run into the wind, and soar.

\section{Flight Memory: November, 13, 2011}

\section{Kitchen table, Calgary, Alberta}

My son and I are working on his math homework. He struggles, nearly daily, with Math homework. He often tells me that Math is dumb. I tell him that Math is magical, but you have to discover the magic. His teacher has sent home a note to parents informing us that they will be working on hundreds charts. My son has just finished creating his own hundreds chart and we are looking for patterns in the page of boxed in numbers. We start to discover patterns in the numbers that make diagonal lines. We start to discover patterns in the numbers if we add the tens to the ones place numbers. The room fills with questions that lift us literally off our seats. Why does that work? What happens on the next diagonal? What is happening? What if we go the other way? We have discovered how to levitate! We transcend the boxes on the page and we have discovered the magic of numbers, the magic of Math! My son turns to me and says, "Mom, you're a really good teacher."

\section{Learning to Fly}

There are four forces that act on an object like a bird or airplane which make it fly. These forces are Thrust, Drag, Gravity and Lift. Philip Phenix (1975) suggests that there are elements to transcendence as well. The four forces active in flight are also at play when we discover and experience transcendent teaching and learning. These same forces allow us to discover the magic of flight in learning. 


\section{Thrust}

Thrust is the force that propels us forward. In our learning we project into the future. We are driven forward by our desire to learn. We yearn to know more about ourselves and our world. Phenix (1975) describes this force as hope and he states that "hope is the mainspring of human existence" (p. 328). We grow and develop as people because of this sense of hope, for "conscious life is a continual projection into the future" (Phenix, 1975, p. 328) and "the impulse to learn presupposes confidence in the possibility of improving one's existence” (Phenix, 1975, pg. 329). This concept of thrust, or hope as Phenix describes it, is our desire to improve, to learn more, to develop as human beings. We each have that yearning to learn. We are born with this desire to discover. Babies spend their days exploring their environment by touching things, licking things, experimenting with their voice and discovering reactions to their voice. They don't need a push to want to learn to roll over, or sit, or crawl, or walk.

We are born wanting to learn. This is the in-born force of thrust that moves us forward in time, and drives us to learn and to grow into new things. Phenix (1975) asserts that "the qualitative test of growth is whether it is consistent with a limitless enrichment of realizations through the progressive actualization of ideal possibilities" (p. 325). We will know that we are growing if we are open to infinite possibilities of what there is to know. We need to be open to going beyond our present place of knowing and being, and explore all that we do not know. In learning and teaching, we are explorers of knowledge, using our questions as our map.

\section{Drag}

Drag:

a resistance force [it] works to slow the forward motion of an object... The drag forces are the opposite of thrust. If the thrust force is greater than the drag force, the plane goes forward, but if the drag force exceeds the thrust, the plane will slow down and stop. (Cislunar Aerospace Inc., 1997, “Drag”, para.1)

The force of drag represents our connection to the past as well as our fear of change. We must be conscious of our past knowledge and where we come from. Phenix (1975) states, "to be humanly alive is to experience each moment as a new creation, to know that this moment, though continuous with the past, is yet a distinct and fresh emergence, which will in turn yield to still further novel realizations" (p. 326). In order to move into this new moment we must acknowledge that we are moving from somewhere. Our past place of knowing and being 
informs our present while creating a tension that helps to give our projection forward a direction and guidance. The new is interconnected with the old, the future is interconnected with the past.

This force of drag is closely related to our fear of change and fear of the unknown. It holds us back from wanting to change. Although this seems negative, there is an element to drag and fear that makes us cautious, thoughtful about our choices. The force of drag in our teaching and learning keeps us focused and aware of responsibilities to our learners. As long as our thrust exceeds our drag we will keep moving forward. But if our fear of change and our reluctance to leave the past exceeds our desire to learn, then we will remain grounded and stuck. However, if we acknowledge our past and present ways of knowing and being and work from them towards our future, we can experience the flight of learning, of transcendence. Awareness and acknowledgement of the past and present allows us and our students to go, to fly ahead as, "The educator thus fosters creativity when he loves and respects the traditional learning, conceived as immanence, to be transformed and rejuvenated in the service of transcendence" (Phenix, 1975, pg. 330).

Flight Memory: May, 2006

Front yard, Calgary, Alberta

Unlatched

I used to guide her exploration into the world, protecting her,

Couching her safely in the curve of my hip.

Now, I must stand back,

Cringing as I watch her crawl, racing away from me.

Her soft, new, inexperienced knees

Scraping along unforgiving pavement.

I scramble behind her tipping and toddling first steps,

My hands hovering and swirling around her,

Frantically trying to predict her falls.

I fear that she will become permanently bruised and callused.

She unlatches my protective hands,

Pushing me away.

I am forced to watch as she stumbles 
Over and over and over,

And I'm always there to swoop in and scoop her up;

Kissing bumps, soothing bruises.

\section{Gravity}

Gravity pulls us down to one spot on the earth. It acts on each of us individually and in this sense it relates to our desire to stay within ourselves and our present abilities and ways of knowing. So often in teaching we are trapped within an individualistic approach to living in the world. We become focused on doing our own thing, with our own class. Each subject area holds its' own weight and is treated and taught in isolation. With this approach to life and to learning we are suggesting that we are each self-sufficient. We live in isolation from the world and we learn about the subjects of the world in isolation from the world.

Phenix (1975) suggests that this "denial of spirituality in the name of individual selfsufficiency or various forms of absolutism, of institution, race, class, nation, tradition, or doctrine, is evidence of this flight from transcendence"(pg. 328). David Jardine (1998) speaks of the integrated curriculum as a way to experience "a truly lived curriculum...that exudes the generativity, movement, liveliness, and difficulty that lies at the heart of living our lives" (pg. 73). This view of the world forces us to acknowledge that we are all connected in sharing the world, just as the birds fly with the awareness of sharing the air. It is through acknowledging and accepting the interconnectedness of ourselves, our knowledge and our world, that we can feel the air we all share, and experience the lift that will allow us to soar beyond the limitations of the force of gravity.

\section{Lift}

Lift is created by the movement of air around the wings of the bird. The air moves faster above the wings than below and this creates a lower pressure above the wings and a stronger force below the wings, and the combination of these forces pulls the bird up into the air (Kazilek, 2009). This rush of air over and around the bird can be seen as representing our sense of wonder and the rush of questions and the infinite knowledge and possibilities that surround us when we venture to learn about the world and about ourselves. Phenix (1975) describes wonder as the "suspenseful tension of consciousness toward the unknown future in response to the attraction of unrealized potentialities" (pg. 332). Wonder creates an air pressure that lifts us up, over, and 
above our present place of knowing and being. It excites our senses and we feel "a wideawakeness", as Maxine Greene (1977) refers to this sensation.

Greene (1977) calls for teachers and learners to experience "works that provoke wideawakeness and an awareness of the quest for meaning, which has so much to do with feeling alive in the world" (pg. 123) and through this exploration into the unknown, into our questions, and into our unrealized potentials, we will be "made aware of the multiplicity of possible perspectives, made aware of incompleteness and of a human reality to be pursued, [and] the individual may reach 'a plane of consciousness of highest tension'"(p.124). She suggests that through opening ourselves to the possibilities and infinity of our potential abilities and knowledge, we will create tension, like the air tension required for flight that will lift us over and beyond, allowing us to experience the flight of transcendence.

\section{Flight Memory: December, 2004}

\section{English 10 classroom, Calgary, Alberta}

My English 10 classroom has divided into two groups. The girls have decided to work together on a project in the library. The boys are staying with me in the classroom. The class is a diverse group, blending students from all levels of previous academic achievement. We have all been reading and exploring William Shakespeare's Romeo and Juliet together. There was the traditional grumbling when we first began, "Why are we reading this? How are we supposed to understand this?"

But we have transcended their first fears with musical performances of the Prologue, dramatic re-enactments of the play, and discussions and writing which have allowed us to travel the streets of Verona questioning the choices of Romeo and Juliet. Now the boys have split into two teams and we are reviewing the play. I call out quotations and each team sends a player to the board to write down the speakers' name. The boys who started our discovery of the play with complaints and fears are now jumping off their seats calling out, "Benvolio! Tybalt! Lady Capulet!" We switch roles and they write down the quotations for the questions. There is a hum and buzzing in the room followed by boys flying around the room, up and over their initial fears and grumblings, beyond their own earlier self-imposed limitations! They have learned to fly through the magic of literature! 


\section{Wonder and Air}

Air allows for flight. The vastness and openness of air allows for exploration and discovery. We need air to breath, to live. Air is as necessary for life as wonder is for learning and for life as well. We yearn for wonder in our lives. We look for it in the suspense and mystery captured by a great novel. We are amazed by the power of a wind storm, invisibly unexpectedly changing the world in which we live. We feel excited by discoveries in science and technology. We feel anxious and curious about different cultures, differences of all kinds. These feelings are created by our sense of wonder. Wonder makes us aware that there is so much more to the world than just ourselves and our present knowledge. Wonder makes us passionate about our lives and about the world. It allows us to live- fully. Wonder also connects us to each other. Air is shared by the world, it ties us to each other. Our wonder makes us aware of our interconnectedness. The questions we pose to Google are answered by learners and teachers around the world. We share our wonder. We are seven billion people all striving to learn the same things, to learn about the world and about ourselves. Wonder breathes life into our learning and our lives.

\section{Flight of Transcendence}

Flight occurs within a series of related tensions. The tension between our thrust forward and our drag backward connects with the gravity that holds us to the earth and the lift, created by air pressure, which pulls us away from the earth into the wonder-filled air. The flight of transcendent teaching and learning shares these same interconnected tensions. Our natural desire to learn creates a tension with our fear of change and connection to the past. Our sense of selfsufficiency and individualism creates a tension with our interconnectedness with the world through our shared sense of wonder. All four of these elements work together, to allow us to fly in and beyond our boxed-in classroom walls.

The sensation of the flight of transcendence is frightening, exhilarating, and peaceful all at the same time. And once we have had a taste of this flight we will yearn to return to the sky over and over again. One experience of flight can inspire us for a lifetime because it makes us aware of the possibility of going over and beyond our present ways of being and knowing, our present capabilities, our selves. We can each remember those moments of transcendence in our learning and teaching that keep us coming back to the classroom in the hope of experiencing it again. The air of wonder blows all around and over us, connecting us to the world and inspiring us to run, and plunge head long into the wind, and soar. $5,4,3,2 \ldots 1$ ! 


\section{Flight in Motion}

The following is a link to a video of a movement piece that I choreographed and recorded $^{1}$ to compliment the written work of my paper, Flight of Transcendence: Exploring Flight as a Metaphor for Transcendent Teaching and Learning. This piece creates a visual embodiment of the experiences of feeling boxed in, the fearful risks of following our inspirations and leaving the safety of our boxes, and the joy and freedom of experiencing a flight of transcendence.

https://www.youtube.com/watch?v=uQcBiCWfUhI

\footnotetext{
${ }^{1}$ I have received permission to include the music, Flying Over the Dateline, by Moby, from moby gratis noncommercial licensing. Music citation included in References.
} 


\section{References}

Cislunar Aerospace, Inc. (1997). Forces in flight. The K-8 aeronautics internet textbook.

Retrieved from

http://www.fi.edu/wright/again/wings.avkids.com/wings.avkids.com/Book/Flight/advanc ed/forces-01.html

Flannery, W. (n.d.). Calculus without tears: An airplane simulator. Berkeley science books. Retrieved from http://www.berkeleyscience.com/airplane.htm

Greene, M. (1977). Toward wide-awakeness: An argument for the arts and humanities in education. Issues in Focus- The Humanities and the Curriculum, 79 (1), 119-125.

Jardine, D. W. (1998). To dwell with a boundless heart. In D. W. Jardine (Ed.), To dwell with a boundless heart: Essays in curriculum theory, hermeneutics, and the ecological imagination (pp. 69-84). New York: Peter Lang.

Kazilek, C.J. (2009, December 17). Feather biology. ASU, School of Life Sciences - Ask a biologist. Retrieved from http://askabiologist.asu.edu/how-do-birds-fly

Moby (2004, July 27). Flying over the dateline. On Play: The B sides. Retrieved from www.mobygratis.com

National Aeronautics and Space Administration. (n.d.) Four forces on an airplane. National Aeronautics and Space Administration. Retrieved from http://www.grc.nasa.gov/WWW/k-12/airplane/forces.html

Phenix, P. (1975) Transcendence and the curriculum. In Pinar (Ed.) Curriculum theorizing: The reconceptualists (p. 319-335) Berkeley, USA: McCutchan Publishing Corporation.

Transcend. (n.d.) In Dictionary.com. Retrieved from http://dictionary.reference.com/browse/transcend 